\title{
A Study on Evaluation of Prevalence And Risk Factors of Post Partum Depression (PPD) in Indian Women
}

\author{
Bijay Khan ${ }^{1}$, Ranjan Basu ${ }^{1}$ \\ ${ }^{1}$ Assistant Professor, Dept. Of Obstetrics And Gynecology; KPC Medical College, Kolkata \\ Fakir Chand Ghosh Lane. Howrah West Bengal. India
}

\begin{abstract}
Objective: To study the prevalence of Post Partum Depression (PPD)in Indian women and to evaluate the risk factors for the development of PPD.

Materials And Methods: This cross-sectional study was done among 278 novel mothers (post delivery 10 days to 3 months) attending post partum clinics of K.P.C.Medical College \& Hospital. Socio-economic factors and detailed obstetric variables were assessed using a programmed questionnaire. PPD was estimated using Edinburgh Postnatal Depression Scale (EPDS). Those who scored more than 13 were considered to have PPD and were referred to a psychiatrist for further evaluation.

Results: Prevalence of PPD was found to be 26.97\%. Among the risk factors,nultiparity, advanced age, low socio-economic condition, minority community, foetal complications andvaginal delivery were found to be the most common.

Conclusion: All mothers especially those with risk factors should routinely be evaluated for the presence of PPD. Counseling should be offered to those women diagnosed with PPD to reduce it's ill effects on herself, her child and other members of the family.
\end{abstract}

Keywords: EPDS; PPD.

\section{Introduction}

Post Partum Depression is a common complication of childbearing [1, 2]. Studies report prevalence rate varying from 10 to $36 \%$ [3, 4]. PPD can range in severity from 'baby blues' that is mild, brief periods of mood disturbance experienced by half to $2 / 3^{\text {rd }}$ of all mothers, and the most severe form- post natal psychosis occurring in 1 out of every 500 novel mothers[5].

Symptoms of PPD include sadness, fatigue, insomnia, decrease or increase in appetite, reduced libido, crying episodes, anxiety and irritability. PPD can have a significant negative impact on the lives of not only the mothers but also other family members including the infants $[6,7]$.

Treatment of PPD may be more challenging because of concerns about the effects of psychotropic drugs on nursing infants. Edinburgh Postnatal Depression Scale (EPDS) [3] is used to screen for depression and it enables health care providers to identify the problem and thereby reduce or prevent serious consequences of PPD. US Food and Drug Administration has not approved any anti-depressant for use during lactation. However untreated depression is also risky for both the mothers and their infants [8]. Here comes the perspective of using alternatives- like counseling, psychotherapy and social support $[9,10]$.

\section{Materials \& Methods}

This cross sectional study was done by the Department of Obstetrics \& Gynecology; in association with the Department of Psychiatry K. P. C. Medical College; Kolkata from April,2015 to March, 2016. Permission was taken from the Ethics committee of the KPC Medical College.

278 women who had given birth in the institute and been with their child for more than 10 days to 3 months were recruited. Informed consent was taken from each woman. Edinburgh Postpartum Depression Scale (EPDS) was used for the study to screen for presence of depression in these women. The scale consists of 10 short statements. A mother checks off one of four possible answers that is closest to how she has felt during the past week. Most mothers easily completed the scale in less than five minutes. Responses are scored $0,1,2$ and 3 based on the seriousness of the symptom. Items 3 and 5 to 10 were scored in reverse order (i.e., $3,2,1$, and 0 ). The total score was found by adding together the scores for each of the 10 items.

A score of more than 13 was taken as diagnostic of PPD. From the history the following parameters were noted in details- parity, total number of living children, sex of the current child, whether the baby had any health problem after delivery, mode of delivery, birth weight of baby, significant antenatal health problem- if any, socio-cultural-economic variables like-age, religion, monthly earning of the family (less than $5000 \mathrm{INR} / \mathrm{month}$ was considered as low income group), support system of child rearing in the family and so on. Mothers who were found to be a single parent, who were already suffering from depression, any major psychosomatic 
disorder or illness, prepregnancy chronic persisting illness like Coronary heart disease (CHD), Chronic Renal Failure (CRF) etc were not included in this study.

\section{Statistical analysis}

Relationships of different factors with development of PPD were assessed by statistical methods like Chi Square and t-test. Possible cases of PPD were counseled in a supportive manner.

Results.

Out of 278 women, we found 75 mothers with PPD (26.97\%). Higher age, multiparity, minority community, low socio-economic conditions were found to be important socio-demographic variables for development of PPD. Amongst obstetric variables, delivering a baby with complications and vaginal delivery are found to be associated with PPD. Sex of the baby surprisingly did not appear to be a significant factor.

\section{Discussion}

There are few studies in our country utilizing EPDS in post partum women. The present study shows that the prevalence of PPD is $26.97 \%$ in our study sample. In a study done in Goa, India with a sample size of 252 women by Patel et al in the year 2002 the prevalence rate of PPD was found to be $23 \%$ which is close to the rate in the present study [11]. However in a similar study done in Pakistan with a sample size of 149 women by Hussain et al in the year 2006 the prevalence rate of PPD was found to be $36 \%$ [4]. This difference is because the socio economic and educational status of the people of Pakistan has been proved to be lower than Indians. As per UNDP Pakistan's presentation in2011,Pakistan's inequality adjusted human development index (HDI) stands to be .346 with an overall loss of 31.4\% where as India's inequality adjusted HDI for 2011 was .392 with an over all loss of $28.3 \%$ [12]. Yelland et al's PPD study conducted in 2010 with a sample size of 4366 women in Australia established the prevalence rate of PPD at 17.4\% which is notably lower than the rate of the present study [13]. This can be credited to the higher educational level and socioeconomic status of Australia over India.The statistics point the inequality adjusted HDI value of Australia at .856 with an over all loss of $23 \%$ [14].

Our study shows that low socio-economic condition and belonging to a minority community put women at a higher risk to develop PPD. Nazmul Hussain et al conducted a study on Muslims in West Bengal trend of population growth and educational status has revealed that Muslims specially women belonging to the Muslim community are socially and economically backward. Muslim women form a crucial section of the sample selected for the present study [15].

Delivering babies with foetal complications has proved to be a risk factor for the development of PPD. Study on PPD done by Patel et al also shows p.value of 0.002 for mothers developing PPD with sick babies [11]. Similarly Kosinska-Kaczynska et al and Adewuya et al also found association with PPD and women delivering a sick baby $[16,17]$.

Multiparity and age of the mothers were also associated with PPD. Mayberry et al and Bjerke et al have found age to be a risk factor for PPD in their studies [18, 19, 20].

Sex of the baby does not appear as a significant factor which is very different from a previous study done by Patel et al in Goa, India in 2002 [11]. It can be noted that increased educational level and changed social structure may have created a positive outlook towards a girl child. From the demographics of India the literacy rate in West Bengal, India is found to be $77.08 \%$ and $71.16 \%$ of women of West Bengal are found to be literate [23].

"Mental health professionals however have an important role in working closely with maternal and child health workers by offering consultative and training services in early detection and referral" [10] - the same is opined by us.

\section{Major limitations of our study which we would like supersede in our future studies on PPD are-}

1) Hospital based (not a concerted approach with the community nurse, other family members of the new mother).

2) Antenatal assessment of depression was not done to correlate with PPD.

3) Prevalence of depression in the new fathers.

\section{Conclusion}

Present study finds significant prevalence rate of PPD in our society. As a primary care physician in the society it should be the duty of the concerned obstetrician to screen all post partum women for depression. A consultation of a Psychiatrist in the process is necessary. PPD may otherwise remain undetected ultimately affecting the health of the mother and the family and finally the society as well. Further studies in a larger population are needed to properly assess the gravity of the problem in our society. 


\section{References}

[1]. Mani Chandran, Prathap Tharyan, Jayaprakash Muliyil, Sulochana Abraham.Post-partum depression in a cohort of women from a rural area of Tamil Nadu, India Incidence and risk factors. The British Journal of Psychiatry.2002;181:499-504.

[2]. K.L. Wisner, B.L. Parry, C. M. Piontek, Postpartum Depression. N Engl J Med.2002.vol. 347, No 3, $194-199$.

[3]. J. L. Cox, J. M. Holden, R. Sagovsky. Detection of postnatal depression: Development of the 10-item Edinburgh Postnatal Depression Scale. Br. J Psy. 1987; 150:782-786.

[4]. Husain N, Bevc I, Husain M, Chaudhry IB, Atif N, Rahman A. Prevalence and social correlates of postnatal depression in a low income country. Arch Womens Ment Health. 2006; 9(4): 197-202.

[5]. http://www.netdoctor.co.uk/health_advice/facts/depressionpostnatal.htm

[6]. Johnson J, Weissman MM, Klerman GL. Service utilization and social morbidity associated with depressive symptoms in the community. JAMA. 1992; 267(11):1478-1483.

[7]. Abdulbari B, Linda MG, Javaid S. Prevalence of psychiatric disorders and associated risk factors in women during their postpartum period: a major public health problem and global comparison. International Journal of Women's Health.2012; 4:191-200.

[8]. Brenda M.Y. Leung, B. J. Kaplan. Perinatal Depression: Prevalence, Risks, and the Nutrition Link- A Review of the Literature. J Am Diet Assoc.2009; 109:1566-1575.

[9]. Appleby, Louis, Rachel Warner, Brian Faragher, Anna Whitton. A Controlled Study of Fluoxetine and Cognitive- Behavioural Counseling in the Treatment of Postnatal Depression.BMJ:932-937. 314. N7085.

[10]. Prabha S Chandra. Post-partum psychiatric care in India: the need for integration and innovation. World Psychiatry. 2004; 3(2): 99100 .

[11]. Patel V, Rodrigues M, DeSouza N. Gender, poverty, and postnatal depression: a study of mothers in Goa, India. Am J Psychiatry. 2002; 159(1): 43-47.

[12]. http://undp.org.pk/images/documents/HDR\%202011\%20Highlights.pdf

[13]. Yelland J, Sutherland G, Brown SJ. Postpartum anxiety, depression and social health: findings from a population-based survey of Australian women. BMC Public Health. 2010; 10: 771

[14]. http://hdrstats.undp.org/en/countries/profiles/AUS.html

[15]. http://papers.ssrn.com/sol3/papers.cfm?abstract_id=1905050

[16]. Kosinska-Kaczynska K, Horosz E, Wielgos M, et al affective disorders in the first week after the delivery; prevalence and risk factors, Gynekol Pol. 2008; 79: 182-5

[17]. Adewuya AO, Fatoye FO, Ola BA, et al socio demographic and obstetric risk factors for post partum depressive symptoms in Nigerian women. J Psychiatr Pract. 2005; 11: 353-8

[18]. Mayberry LJ. Horowitz JA, Declerkq E. Depression symptom prevalence and demographic

[19]. risk factors among US women during the first two years post partum. J Obstet Gynecol Neonatal

[20]. Nurs. 2007; 36: 542-9.

[21]. Bjerke SE, Vangen S, Nordhagen R, et al post partum depression among Pakistani women in

[22]. Norway: Prevalence and risk factors, J Maternal Foetal Neonatal Med. 2008; 7: 1-6

[23]. http://www.scitechnol.com/JWHIC/JWHIC-1-101.php

[24]. Gausia K, Fisher C, Ali M, Oosthuizen J. Antenatal depression and suicidal ideation among rural Bangladeshi women: acommunity-based study. Arch Womens Ment Health. 2009; 12(5): 351-358.

[25]. Hobfoll SE, Ritter C, Lavin J, Hulsizer MR, Cameron RP. Depression prevalence and incidence among inter-city pregnant and postpartum women. J Consult Clin Psychol. 1995; 63(3): 445-453.

[26]. http://www.mapsofindia.com/census2011/literacy-rate.html

Table 1. Socio-demographic and Clinical Profile

\begin{tabular}{|c|c|c|c|c|}
\hline \multicolumn{2}{|l|}{ Trait } & $\begin{array}{l}\text { Depressed } \\
(\mathrm{N}=75)\end{array}$ & $\begin{array}{l}\text { Non-depressed } \\
(\mathrm{N}=203)\end{array}$ & $\begin{array}{l}\mathrm{P} \\
-\end{array}$ \\
\hline \multirow[t]{2}{*}{ Income } & Middle & 27 & 158 & \multirow[t]{2}{*}{0.0001} \\
\hline & Low & 48 & 45 & \\
\hline \multirow[t]{2}{*}{ Religion } & Hindu & 63 & 141 & \multirow[t]{2}{*}{0.01} \\
\hline & Muslim & 12 & 62 & \\
\hline \multirow{2}{*}{$\begin{array}{l}\text { Delivery } \\
\text { Type }\end{array}$} & LSCS & 54 & 185 & \multirow[b]{2}{*}{0.0001} \\
\hline & $\begin{array}{l}\text { Vaginal } \\
\text { Delivery }\end{array}$ & 21 & 18 & \\
\hline \multirow{2}{*}{$\begin{array}{l}\text { Health of } \\
\text { baby }\end{array}$} & Sick baby & 15 & $\mathrm{O}$ & \multirow[b]{2}{*}{0.0001} \\
\hline & $\begin{array}{l}\text { Healthy } \\
\text { baby }\end{array}$ & 60 & 203 & \\
\hline \multirow[t]{3}{*}{ Sex of baby } & Male & 36 & 99 & \multirow{3}{*}{0.43} \\
\hline & Female & 36 & 101 & \\
\hline & Twin & $\begin{array}{l}3 \\
--------\end{array}$ & $\begin{array}{l}3 \\
----------\end{array}$ & \\
\hline Total & & 75 & 203 & $26.97 \%$ \\
\hline ---------- & ------------ & ------------ & --------------- & ---------- \\
\hline
\end{tabular}

Table 2

\begin{tabular}{|l|l|l|l|l|l|l|l|}
\hline \multirow{2}{*}{ Trait } & \multicolumn{2}{|l|}{ Depressed } & \multicolumn{2}{l|}{ Non-depressed } & & \multirow{2}{*}{} & \\
\cline { 3 - 8 } & Mean & SD & Mean & SD & t & df & $\mathrm{p}$ \\
\hline $\begin{array}{l}\text { Age of mother } \\
\text { (years) }\end{array}$ & 27.02 & 5.81 & 25.31 & 5.46 & -2.227 & 277 & .027 \\
\hline Parity & & & & & & & \\
\hline
\end{tabular}




\begin{tabular}{|ll|l|l|l|l|l|l|l|}
\hline $\begin{array}{l}\text { Birth weight } \\
\text { baby }(\mathrm{kg})^{*}\end{array}$ & of & 2.648 & .496 & 2.871 & .478 & 3.392 & 274 & .001 \\
\hline
\end{tabular}

* 3 missing data for birth weight. So among the sample, 204 non-depressed and 72 depressed.

Table-3.Shows overall prevalence of PPD in different study groups.

\begin{tabular}{|l|l|l|l|l|l|}
\hline Country & $\begin{array}{l}\text { Age group in } \\
\text { years }\end{array}$ & Sample size & Prevalence rate & Year of Study & Reference \\
\hline $\begin{array}{l}\text { India, Current } \\
\text { study }\end{array}$ & $19-36$ & 279 & $26.88 \%$ & $2010-2012$ & Nandi et al \\
\hline India, Goa & $18-40$ & 252 & $23 \%$ & 2002 & Patel et al [11] \\
\hline Bangladesh & $17-41$ & 361 & $33 \%$ & 2009 & $\begin{array}{l}\text { Gausia et al } \\
\text { [21] }\end{array}$ \\
\hline Pakistan & $17-40$ & 149 & $36 \%$ & 2006 & Husain et al [4] \\
\hline Australia & $16-35$ & 4366 & $17.4 \%$ & 2010 & $\begin{array}{l}\text { Yelland et al } \\
\text { [13] }\end{array}$ \\
\hline USA & $17-47$ & 192 & $23.4 \%$ & 2001 & $\begin{array}{l}\text { Hobfoll et al } \\
{[22]}\end{array}$ \\
\hline
\end{tabular}

